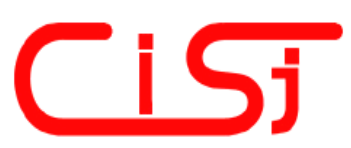

\title{
SMART VEST AND MONITORING SYSTEM FOR AIRSOFT SPORT-GAMES USING VIBRATION SENSOR
}

\author{
Giva Andriana Mutiara, Periyadi, Andry Dupti Agnas, Velly Darma \\ Applied Science School, Telkom University, Indonesia \\ giva.andriana@tass.telkomuniversity.ac.id, periyadi@tass.telkomuniversity.ac.id, \\ andrydupti@gmail.com, velidarma@gmail.com
}

Paper history:

Received 18 March 2019

Received in revised form 14 February 2020

Accepted 25 May 2020

Available online 14 June 2018
Keywords:

Airsoft Sport Games;

Smart Vest;

Monitoring Game;

Airsoft Gun.

\begin{abstract}
Airsoft gun is a replica of weapons used for airsoft sports-games activities. These sport-games are usually equipped with ball bullet type, vest protector, helmet and sunglasses. Rules of the game are defined by prioritizing the honesty of each player if hit by a shot. This becomes a weakness and is misused by the player. To reduce these two impacts, this paper proposed an innovation by developing vest that can detect laser light and the bullet. Those hits then connected to the database and also monitoring system. This system is constructed using Light Dependent Resistor, Raspberry Pi 3, motor vibration sensor, piezoelectric, LED lamp, and buzzer. By utilizing the MAC Address of Raspberry Pi 3, the player can be recognized and the counter of the remaining lives of the player will be displayed. The player's life can be determined by a shoot, if point 25 is set for one shoot, then the player declares the game is over after four hits. Based on the testing results, this research can help to do these sport-games informative, efficient and fairly.
\end{abstract}

Copyright (C) Research Institute for Intelligent Computer Systems, 2020. All rights reserved.

\section{INTRODUCTION}

Airsoft is a sport-game that simulates military or police activities using replica firearms or airsoft guns. Nowadays, the airsoft game becomes so popular and has a growing community and active in social networking. This is a kind of live-action game and war simulation that rushes adrenaline with special attraction. A replica weapon with a bullet made of plastic seeds with a firepower range of 300 $-450 \mathrm{fps}$ [1] is used in this game. The players must wear a helmet, vest, goggles (special glasses), and special shoes if the game is held in the forest to prevent being impaled by a foreign object on the player's foot [2]. The weakness in this game often happens, in every game, there is always a zombie player. Zombie player is a player who has been hit by the opponent but does not confess and still continue the game since the environmental conditions become the effect of the player's accuracy because the bullet used is very light.

Meanwhile, this sport-game is also dangerous and harmful. In the airsoft gun games, if the player does not wear the safety equipment, the injury would have happened. The use of hard round plastic bullets can harm the player, most of the injured players are young males [3]. Usually, it can injure the eyes of the player.

Several studies are researching to detect the damage that injured by a shot of the soft gun. A study from Soroka University Medical Center, describe the injured eyes from airsoft gun bullets, record real-time impact of every bullet that hit the eyes with different speed and conducts the investigation in histopathology [4-6].

Other research was done by a researcher from the University of Central Florida and U.S Army Research Institute, Orlando, Florida. The collaboration research makes an evaluated simulation interface for integrating a wearable computer into load-bearing equipment from a soldier's in order to provide better training through increased realism and immersion. They make a comparison between the simulator and the integrated wearable computer. But unfortunately, the results obtained are not as expected. The use of an integrated wearable computer interface causes 
symptoms of a disease stronger than the disease simulator. The visual surveillance was also developed to recognize the gun from the monitor or Closed Circuit Television (CCTV) [7].

There is not much research that discusses smart vests that are applied in the sports field. But, this research will adopt several developments carried out by several researchers who discuss smart vests in other fields. The monitoring system in this research would adopt the research conducted by Afghani et Al. He applied the smart vest to monitor errors that happened in the medical system using AT-89C2051 [8]. The differences are the following: this research will monitor the life-time of the player using Raspberry Pi 3 [9] since this tool can configure as a good server [10]. The concept of hit that will be used in this research is adopted from the LaserTag concept [11] since the use of lasers in weapons allows real-time and high precision on the intended target without obstacles in the environment.

To detect the hit in Real-Time target hit from the shouter, the automatic hit detection system will be inserted a technique that is reported in the research at Naval Surface Warfare Center (NSWC) [12, 13]. The remote module consists of sensor devices, controllers, and communication. The communication module NSWC uses Zigbee. While in this research, we will utilize MAC address [14] from each tool applied in the system, as described in the research conducted by Abedi et al $[15,16]$.

An optimized digital product is used in Airsoft gun sport. The gun uses AirGun that has 6-mm bullets and IR-LED [17]. A complete helmet, vest, and gun were integrated into the system; however, the system was not equipped with the gunlock system as enhanced in our research. The sensor will be placed in the vest as a wearable vest for health monitoring as a vital body-worn sensor [18].

Based on all those literature studies, the implementation of the smart vest in the sports game will have the features as follows:

- Hit detection can be detected in the real-time system.

- A smart vest that can lock the gun when the player declares the game is over

- Monitoring system supervising the game from failure and misuse.

- The system that is able to save the whole game in a database.

This paper will be organized as follows: section one describes the introduction of the paper. Section two explains the proposed system. Section three discusses the testing and the result of the system. Section four outlines the conclusion and future work that can be developed from this research.

\section{PROPOSED SMART VEST SYSTEM AND MONITORING}

The Innovations that will be developed and implemented in this research aim at overcoming the problem that has been described in the introduction. This system is divided into three systems, namely, a smart vest hit detection system, a gun-lock system, and a monitoring system. Some tools will be integrated into weapons and vests to become a smart monitoring system.

The stages of designing a smart vest system can be seen in Fig. 1. The stages used to guide the research so that the goal can be gained and reached.

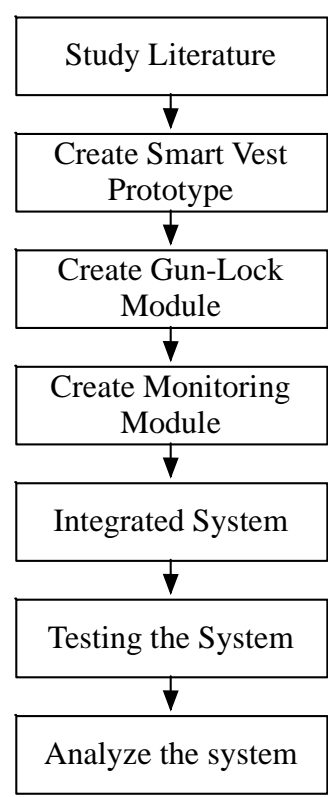

Figure 1 - Stages of the Research

The study of literature has been described in the introduction chapter. By studying various kinds of technology adopted and inserted into the smart vest system, the next stages are describing how the proposed prototype of the smart vest system is created, the gun-lock module and the monitoring module is designed.

\subsection{SMART VEST PROTOTYPE SYSTEM}

Smart Vest Prototype system uses a light sensor that is modified to detect laser light and is connected to the Raspberry $\mathrm{Pi}$, which will process sensor data and send it to the database. Raspberry $\mathrm{Pi}$ in the system used as a place to run the sensor logic program and store data for each MAC address [19] sent from the trigger of the laser sensor. The response given directly to the hit player is a vibration generated by the vibrator motor sensor, LED lights, and sound buzzer if the player has been completely eliminated. This system is expected to minimize the cheating of the failure by the player. 
Light Dependent Resistor or also often called photoresistor, is one of the passive electronic components. Basically, a photoresistor has a different variation of resistance depending on the intensity of the incoming light and on the surface of the ceramic photoresistor [20]. The resistance to the photoresistor in the dark is very high. It can reach around $1 \mathrm{M} \Omega$, but when there is lightly falling above the photoresistor material, the resistance can drop to around 0-100 K $\Omega @ 10$ lux, 2-4 K $\Omega @ 100$ lux. LDR will be used as a sensor to detect the laser gun. The graph of the light intensity can be seen in Fig. 2.

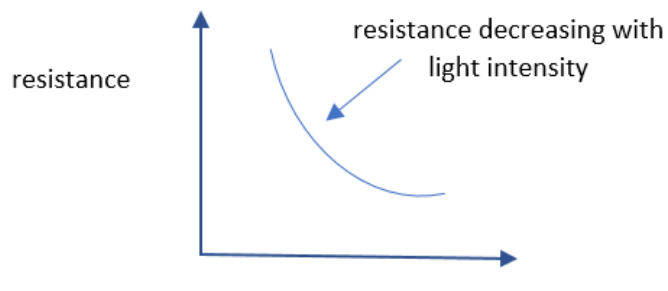

light intensity

Figure 2 - Light Intensity Against LDR

To build a smart vest system, the required tool, component hardware and software can be defined in Table 1.

Table 1. Hardware and Software

\begin{tabular}{|c|c|c|}
\hline & Tools & Function \\
\hline \multirow[t]{9}{*}{ Hardware } & Raspberry Pi 3 B & $\begin{array}{l}\text { Used as a system to } \\
\text { run programs and } \\
\text { data storage on vest }\end{array}$ \\
\hline & $\begin{array}{l}\text { Node MCU using } \\
\text { Arduino Uno }\end{array}$ & $\begin{array}{l}\text { Used to collect data } \\
\text { from sensors }\end{array}$ \\
\hline & Power bank & $\begin{array}{l}\text { Used to deliver the } \\
\text { energy to the system }\end{array}$ \\
\hline & Servo SG90 & $\begin{array}{l}\text { to lock the trigger in } \\
\text { Airsoft Gun }\end{array}$ \\
\hline & $\begin{array}{l}\text { Light Dependent } \\
\text { Resistor }\end{array}$ & $\begin{array}{l}\text { Used to detect the } \\
\text { laser light on the vest }\end{array}$ \\
\hline & Ceramic Capacitor & $\begin{array}{l}\text { Works for temporary } \\
\text { power storage on the } \\
\text { circuit }\end{array}$ \\
\hline & $\begin{array}{ll}\text { Light } & \text { Emitting } \\
\text { Diode } & \end{array}$ & $\begin{array}{l}\text { marking the status of } \\
\text { the condition on the } \\
\text { player's vest }\end{array}$ \\
\hline & $\begin{array}{l}\text { Vibration motor } \\
\text { sensor } \\
(\text { Piezoelectric) } \\
\end{array}$ & $\begin{array}{l}\text { Used for auto sign if } \\
\text { laser sensor is shot in } \\
\text { vibration }\end{array}$ \\
\hline & Buzzer & $\begin{array}{l}\text { Used as a marker if } \\
\text { the sensor is exposed } \\
\text { by a laser or player } \\
\text { has been eliminated }\end{array}$ \\
\hline \multirow[t]{4}{*}{ Software } & Python & Main program \\
\hline & Raspbian & Operating system \\
\hline & Fire Base & Database system \\
\hline & PHP & $\begin{array}{l}\text { To display the } \\
\text { temporary data from } \\
\text { laser sensor result }\end{array}$ \\
\hline
\end{tabular}

The prototype of the smart vest can be seen in Fig. 3. The smart vest is integrated by adding a node MCU of Arduino Uno as a place to run the sensor logic program and also adding five firing points from each target consisting of several LDRs and vibration sensors. The LDR arranged and blocked by the dark cover to avoid interferences from outside light while the vibration sensor is used to catch the bullet from the weapons. The five-firing point is placed in the five areas in the body. Four of them were placed in the body area that was not fatal, while the remaining one was placed in the fatal area, in the heart of the player located in the left chest of the player. The four-firing point is divided into $25 \%$ of the healthy player as a lifetime for each sensor reducing point, while the fatal firing point is pointed out of $100 \%$ of the healthy player.

All the information will be displayed in the Webbased monitoring system. The database system will be stored and saved for each MAC address of the Raspberry Pi.
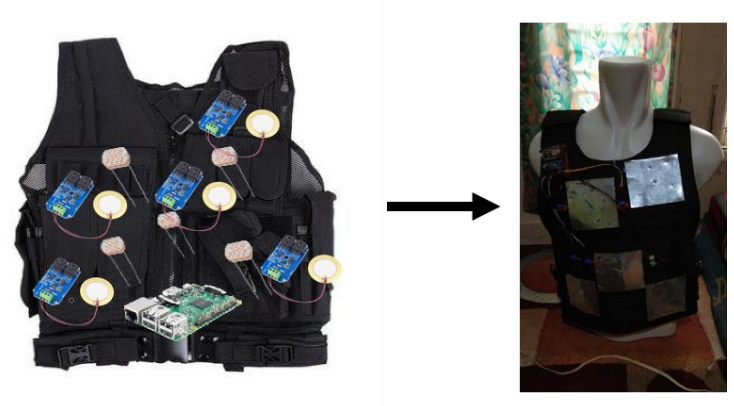

Figure 3 - Smart Vest Design

\subsection{GUN-LOCK SYSTEM}

After creating the smart vest module, the next stage is designing and programming the gun-lock system module. Servo SG90 [21, 22] is applied as a trigger to lock the airsoft gun. According to that condition, the players who are already game over in the game cannot continue playing in the game. Fig. 4 shows the airsoft gun applied with servo SG90 and Arduino Uno.

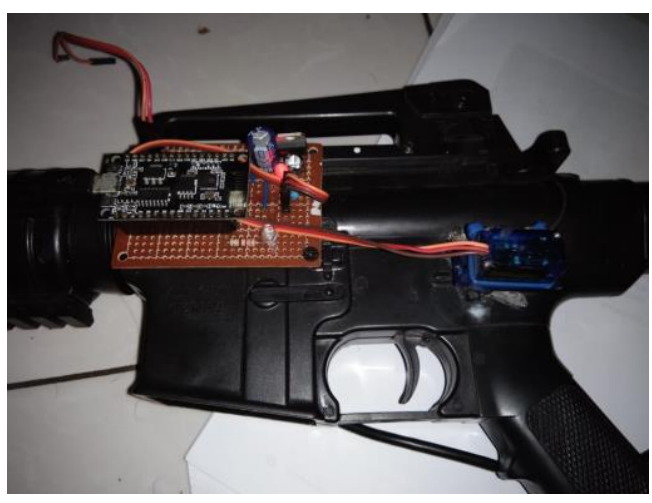

Figure 4 - Airsoft Gun Servo Lock SG90 
The workflow for the gun-lock system can be seen in Fig. 5. When the game starts, all the players are in the default state. All the five-firing points are installed in the vest. When a player is hit by a shot, the program will run into the condition of checking the life value of the data entered from the sensor hit by the shot. If the sensor hits a fatal point located on the player's left chest, the player resumes as a game over, and the player cannot continue the game. If the sensor hit by bullet or light is not located at the fatal point, the lifetime value of the player only reduces by $25 \%$ of the lifetime of the player, the player can continue the game until the life value received by the system is equal to $0 \%$.

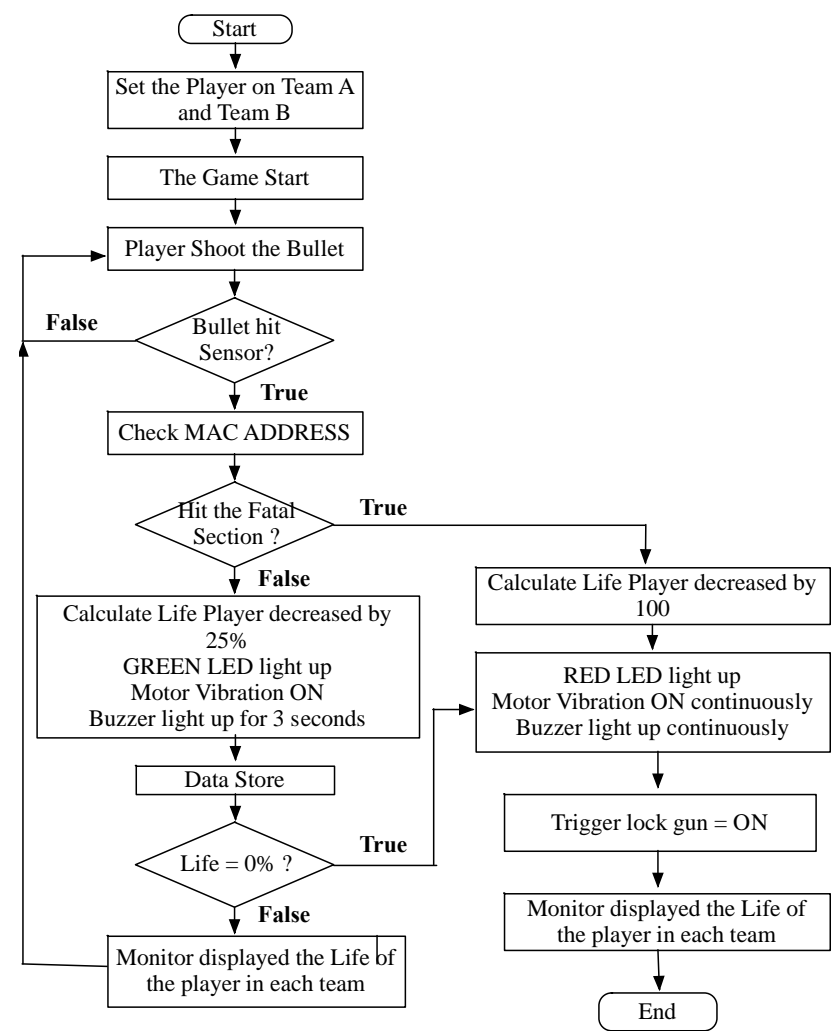

Figure 5 - Flowchart of Smart Vest System

The condition of the shot based on the placing of the firing sensor will get a signal with the active green LED and turned on the buzzer for three seconds. The vibration sensor motor also acts as a notification indicator for the player. The sensor that is placed on the player's left chest as a fatal area, if hit by a single shot, will instantly eliminate the player's life, and the LED indicator will light red and turn on the buzzer continuously. The motor also vibrates continuously as a self-signed indicator for the player. While this condition has happened, the trigger lock gun will be activated and the gun cannot do a firing. The player who has a gun locked must leave the game. So, all the running game is well recorded and supervised on the monitor.

\subsection{MONITORING SYSTEM}

After designing the prototype of a smart vest system and the gun-lock module, the next stage is conducting the monitoring system to supervise the running game from the game area. The diagram block of the monitoring system module can be seen in Fig. 6.

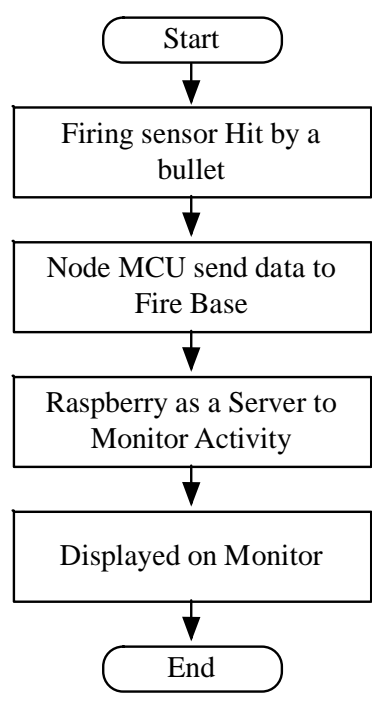

Figure 6 - Diagram Block Monitoring System Module

The monitoring system itself is designing the data from the smart vest sent into the Firebase from Node MCU through Wi-Fi. The webserver will take the data from the Firebase to be displayed in the monitoring system. The database in the monitoring system is using Firebase. Authentication from a google account is needed to access the database. The data can store the data in the form of two teams. Each team can configure the player until ten players per each team. The interface of the monitoring system of two teams with five players in each team can be seen in Fig. 7.

\begin{tabular}{|c|c|c|c|c|c|}
\hline \multicolumn{6}{|c|}{ MONITORING SYSTEM } \\
\hline \multicolumn{3}{|c|}{ TEAM A } & \multicolumn{3}{|c|}{ TEAM B } \\
\hline Player & Life & Remark & Player & Life & Remark \\
\hline BOTA & $100 \%$ & & BOTF & $100 \%$ & \\
\hline Вотв & $0 \%$ & Game-Over & BOTG & $100 \%$ & \\
\hline BOTC & $75 \%$ & & BOTH & $75 \%$ & \\
\hline BOTD & $100 \%$ & & BOTI & $100 \%$ & \\
\hline BOTE & $100 \%$ & & BOTJ & $100 \%$ & \\
\hline
\end{tabular}

Figure 7- Interface of Monitoring System

All the system modules then integrated as a system of the smart vest and monitoring system for the airsoft sports game. The integrated system can be seen in Fig. 8. The smart vest prototype sends the data through the node MCU. The data in the smart 


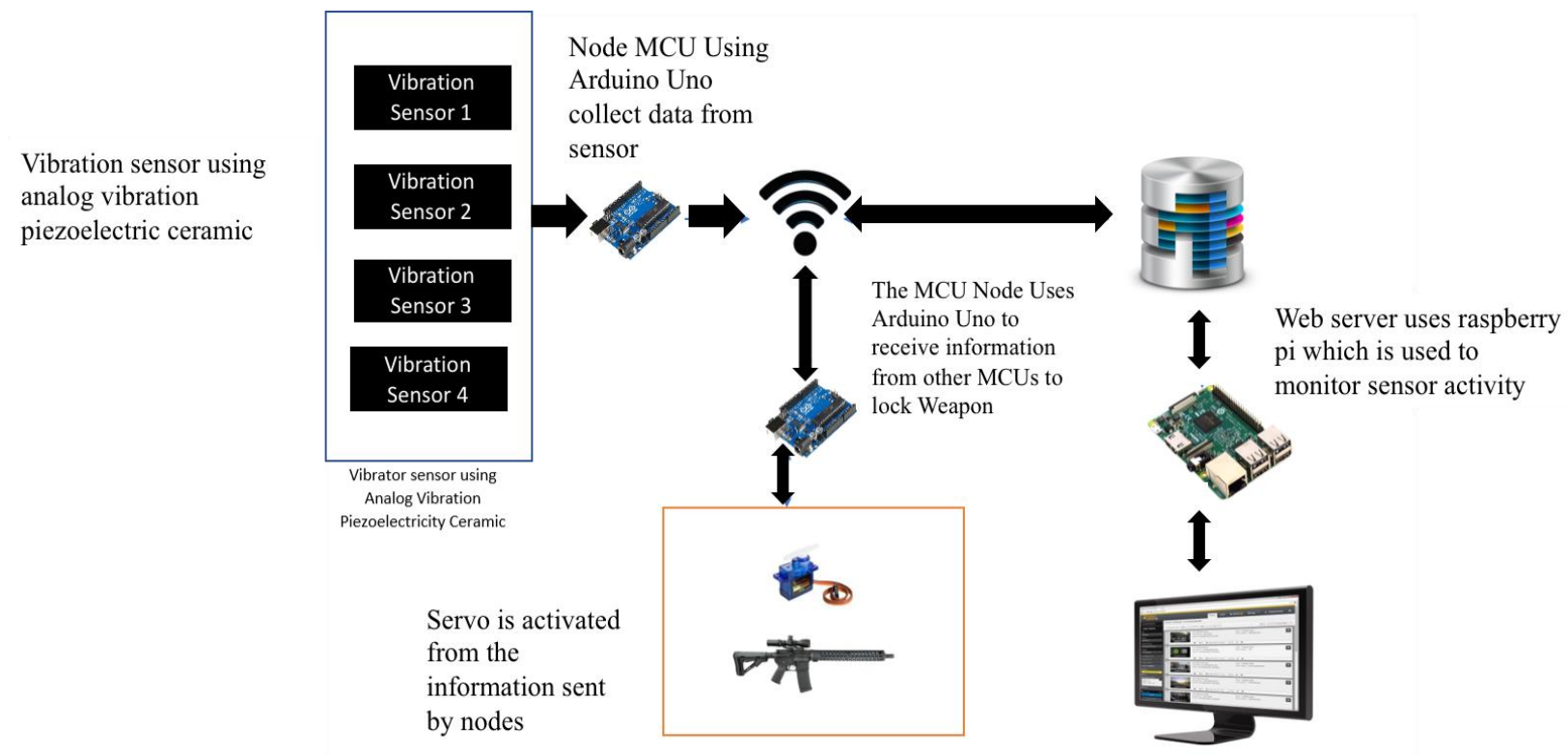

Figure 8- Diagram Block of Integrated System

vest is collected by the Arduino Uno on Node MCU. The gun-lock system will activate the servo if the data sent by the other MCU is configuring the game due to the conditions of the players. The monitoring system supervises all the actions from smart vest prototype and gun lock module through a web-server that utilizes Raspberry Pi to monitor sensor activity.

\section{TESTING AND RESULT}

This research is tested by several scenarios. All the scenarios are conducted to have a good performance of the smart vest monitoring system. The several scenarios are described as subchapters below.

\subsection{TESTING SENSOR SYSTEM}

This test is conducted to determine the maximum distance of the sensor that can read the light emitted received by the LDR that receives laser light shots. The vest is given the gunshot by using a green laser with $1000 \mathrm{~mW}$ transmit ion power with a range up to 25 meters. The LDR sensor cannot use the laser beam over 25 meters because of the spread of the laser beam. The sensor testing can be seen in Fig. 9.
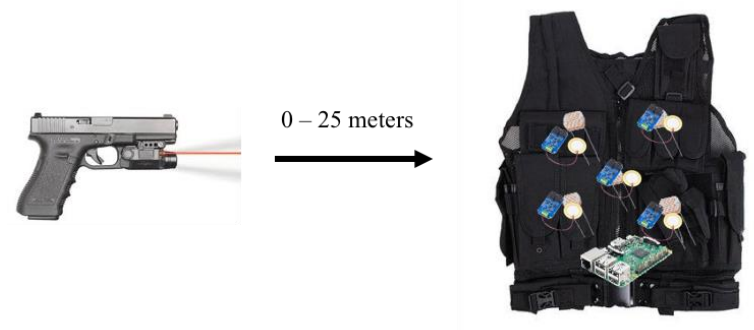

Figure 9- Testing Sensor
The response of testing sensor against the range of the hitting is described in Table 2. As we can see in Table 2, the sensor is tested within the range from 5 to 25 meters. The test was stopped at a distance of 25 meters due to the relatively long shooting distance and various factors that caused the shooting to be no longer accurate. The time response also increases.

Table 2. Sensor LDR Response Testing Result

\begin{tabular}{|c|c|l|}
\hline $\begin{array}{c}\text { Test } \\
\text { Range } \\
\text { (meter) }\end{array}$ & $\begin{array}{c}\text { Time } \\
\text { (second) }\end{array}$ & \multicolumn{1}{c|}{ Remarks } \\
\hline 5 & 1 & $\begin{array}{l}\text { Close distance allows direct } \\
\text { light on the LDR }\end{array}$ \\
\hline 10 & 1 & $\begin{array}{l}\text { At a distance of 10 meters, } \\
\text { the focus of laser light is still } \\
\text { high, the LDR receives the } \\
\text { laser light }\end{array}$ \\
\hline 15 & 2 & $\begin{array}{l}\text { At a distance of 15 meters the } \\
\text { LDR can still receive laser } \\
\text { light which is fired with a } \\
\text { little scatter spread from the } \\
\text { laser light }\end{array}$ \\
\hline 20 & 3 & $\begin{array}{l}\text { At a distance of } 20 \text { meters the } \\
\text { external light has affected the } \\
\text { laser light thus the LDR } \\
\text { response slow }\end{array}$ \\
\hline 25 & - & $\begin{array}{l}\text { At a distance of 25 meters } \\
\text { laser light has been so much } \\
\text { interfered with other light so } \\
\text { it is necessary to set the LDR } \\
\text { resistance limit }\end{array}$ \\
\hline
\end{tabular}

The second scenario is the testing sensor piezoelectric ceramic using airsoft gun Tokyo Marui 1911. This test was conducted to determine the shooting range of the airsoft gun since the bullet was 
0.12 grams weight. This distance testing is done to determine the effectiveness of the sensor and the pressure generated by the airsoft gun. The result can be seen in Table 3 .

Table 3. Sensor Piezoelectric Ceramic Response Testing Result

\begin{tabular}{|c|c|l|}
\hline $\begin{array}{c}\text { Test Range } \\
\text { (meter) }\end{array}$ & $\begin{array}{c}\text { Time } \\
\text { (second) }\end{array}$ & \multicolumn{1}{|c|}{ Remarks } \\
\hline 5 & 1 & $\begin{array}{l}\text { Sensor can detect the hitting } \\
\text { of the firing bullet }\end{array}$ \\
\hline 10 & 1 & $\begin{array}{l}\text { Sensor can detect the hitting } \\
\text { of the firing bullet }\end{array}$ \\
\hline 15 & 2 & $\begin{array}{l}\text { Sensor can detect the hitting } \\
\text { of the firing bullet }\end{array}$ \\
\hline 18 & - & $\begin{array}{l}\text { The sensor hard to sense the } \\
\text { hit, since the firing bullet is } \\
\text { not enough to push the sensor } \\
\text { and activate the LED as a } \\
\text { sign of being hit by the } \\
\text { player }\end{array}$ \\
\hline
\end{tabular}

\subsection{GUN-LOCK TESTING SYSTEM}

This test was carried out to test the servo on the weapon to lock the trigger automatically from node MCU. The test was conducted for several shots, as outlined in Table 4. Based on the table, it can be stated that all several scenarios are appropriated with the workflow to defined lock or unlocked the trigger. There are five sensors placed inside the vest. The sensors S1 until S4 represent the sensor node, which is located not in the fatal section of the chest, but the S5 represents the sensor node located in the fatal section of the players (left chest). This test is integrated with the LED and vibration sensor testing.

The first attempt of this testing, the vest is shot many times by the gun, and four of them hit the sensor_1 (S1), sensor_2 (S2), sensor_3 (S3), and sensor_4 (S4). The counter of life remains zero, and the player is game over. The trigger also locked the gun, LED turn RED, and the vibration sensor vibrates continuously.

In the second attempt, many bullets shoot the vest. One of the bullets hit the sensor, which is placed on the left chest of the vest (S5). The life counter immediately shows zero. It means the player is also game over as the first attempt condition. The trigger also locked the gun, LED turn RED, and the vibration sensor vibrates continuously.

In the third attempt, the vest is reshot many times by the gun. The result indicates two sensors located not in the fatal area shot. The life counter indicates $50 \%$, the player continues the game, and the trigger did not generate the servo to lock the gun. LED indicates green light, and the sensor vibrates only three times.
In the last attempt, the vest is reshot by many bullets - two of the sensor shot. One is not located at the fatal area while the other one shot the sensor, which was located in the deadly area. Since the bullet shoots the lethal area, the trigger is generating the servo to lock the gun, and the player is considering the game over. The LED turns to RED, and the sensor vibrates continuously.

Based on those attempts, it can be stated that the Gun-lock system is running appropriate with the scenario.

Table 4. Gun-Lock Testing System

\begin{tabular}{|l|l|l|l|l|}
\hline Scenario & Life & Trigger & LED & Vibration \\
\hline $\begin{array}{l}\text { Four shots } \\
\text { on all } \\
\text { sensors }\end{array}$ & $0 \%$ & Locked & Red & Continue \\
\hline $\begin{array}{l}\text { One Shots } \\
\text { on Fatal } \\
\text { area (S5) }\end{array}$ & $0 \%$ & Locked & Red & Continue \\
\hline $\begin{array}{l}\text { Two shots } \\
\text { on two } \\
\text { sensors } \\
\text { without } \\
\text { fatal area }\end{array}$ & $50 \%$ & Unlocked & Green & $\begin{array}{l}3 \text { second } \\
\text { vibrates }\end{array}$ \\
\hline $\begin{array}{l}\text { Two } \\
\text { sensors } \\
\text { shots, one } \\
\text { in fatal } \\
\text { area (S5) } \\
\text { and on } \\
\text { non-fatal } \\
\text { area sensor }\end{array}$ & $0 \%$ & Locked & Red & Continue \\
\hline
\end{tabular}

\subsection{MONITORING TESTING SYSTEM}

This testing conducted to examine monitoring the life of all players during the game. This monitoring test is performed for two teams. Team A and Team B. Each team has four players. The monitor display is designed in such a way that the supervision of the players in each team can be well monitored.

This testing is attempted by two scenarios. In the first scenario, two teams attack each other. After a couple of minutes, one of the players in team A (BOTB player) was hit and game over, while in team B, player BOTF and BOTH are game over. The guns of all players who are game over are locked while the other players in both teams can continue the game.

The second scenario is as the first scenario, two teams attack each other. The result in the Table shows that the game ends at the moment when all the players in team B have been game over, and all the guns in team B are locked.

The result can be seen in Table 5. All the scenarios can be monitored properly and do not influence the result even though there is a delay as shown in Table 3 and Table 4. 
Table 5. Monitoring Testing

\begin{tabular}{|c|c|c|c|c|c|c|c|}
\hline \multicolumn{2}{|c|}{ Scenario } & & & & & & \\
\hline Team A & Team B & \multicolumn{6}{|c|}{ Display } \\
\hline \multirow{7}{*}{$\begin{array}{l}\text { One player Four } \\
\text { shots on all } \\
\text { sensors }\end{array}$} & \multirow{7}{*}{$\begin{array}{l}\text { Two player } \\
\text { shots all the } \\
\text { sensor }\end{array}$} & \multicolumn{6}{|c|}{ MONITORING SYSTEM } \\
\hline & & \multicolumn{3}{|c|}{ TEAM A } & \multicolumn{3}{|c|}{ TEAM B } \\
\hline & & Player & Life & Remark & Player & Life & Remark \\
\hline & & BOTA & $100 \%$ & & BOTE & $0 \%$ & Game-Over \\
\hline & & ВОТВ & $50 \%$ & & BOTF & $0 \%$ & Game-Over \\
\hline & & BOTC & $25 \%$ & & BOTG & $0 \%$ & Game-Over \\
\hline & & BOTD & $75 \%$ & & BOTH & $0 \%$ & Game-Over \\
\hline \multirow{7}{*}{$\begin{array}{l}\text { All the player } \\
\text { plays safe }\end{array}$} & \multirow{7}{*}{$\begin{array}{l}\text { All player } \\
\text { game over }\end{array}$} & \multicolumn{6}{|c|}{ MONITORING SYSTEM } \\
\hline & & \multicolumn{3}{|c|}{ TEAM A } & \multicolumn{3}{|c|}{ TEAM B } \\
\hline & & Player & Life & Remark & Player & Life & Remark \\
\hline & & BOTA & $100 \%$ & & BOTE & $100 \%$ & \\
\hline & & ВОтВ & $0 \%$ & Game-Over & BOTF & $0 \%$ & Game-Over \\
\hline & & BOTC & $75 \%$ & & BOTG & $75 \%$ & \\
\hline & & BOTD & $100 \%$ & & BOTH & $0 \%$ & Game-Over \\
\hline
\end{tabular}

\section{CONCLUSION}

The smart vest and monitoring system using the embedded system vibration sensors, Raspberry Pi and node MCU can work properly. The smart vest response the hit in real-time (only one until two seconds) and can be monitored from the postal monitoring game area. The addition of integrated LEDs, buzzers, and lock feature in the gun makes the airsoft gun game controlled on the basis of its function. According to the traditional, manual, and unattended air soft gun game, the game with this embedded application also can be monitored by the administrator, properly from the remote area and makes the game play fairly.

In the future works, this system can be enhanced by adding some tools like using the Global Positioning System to supervise the players from monitoring post. The system can also be enhanced using API server and applied in IoT applications

\section{ACKNOWLEDGMENT}

We would like to thank PPM Telkom University for the funding the publication fees to this research. We also thank to Research Group Laboratory of Network and Embedded System (ENS) Research Group of School of Applied Science Telkom University.

\section{REFERENCES}

[1] Crisis Group, "Illicit Arms in Indonesia," Policy Briefing, Asia Briefing $\mathrm{N}^{\circ} 109$, Jakarta/Brussels, 6 September 2010, pp. 1-20.

[2] S. C. Mukhopadhyay, "Wearable sensors for human activity monitoring: A review," IEEE Sens. J., vol. 15, no. 3, pp. 1321-1330, 2015.

[3] A. Kratz, J. Levy, D. Cheles, Z. Ashkenazy, E. Tsumi, and T. Lifshitz, "Airsoft gun-related ocular injuries: Novel findings, ballistics investigation, and histopathologic study," Am. J. Ophthalmol., vol. 149, no. 1, pp. 37-44.e2, 2010.

[4] S. Khalaily, E. Tsumi, T. Lifshitz, A. Kratz, and J. Levy, "Airsoft gun-related ocular injuries: Long-term follow-up," Journal of American Association for Pediatric Ophthalmology and Strabismus. (AAPOS), vol. 22, issue 2, pp. 107-109, 2018.

[5] M. Nili Ahmadabadi, R. Karkhaneh, A. Kord Valeshabad, A. Tabatabai, M. J. Jager, and E. Nili Ahmadabadi, "Clinical presentation and outcome of perforating ocular injuries due to BB guns: A case series," Injury, vol. 42, no. 5, pp. 492-495, 2011.

[6] J. C. Fleischhauer, D. Goldblum, B. E. Frueh, F. Koerner, "Case reports and small case series," ARCH Ophthalmol, vol. 117, pp. 14221439, 1999.

[7] R. K. Tiwari and G. K. Verma, "A computer vision based framework for visual gun detection using Harris interest point detector," Procedia Comput. Sci., vol. 54, pp. 703-712, 2015.

[8] S. Afghani, M. Ali, and S. Safdar, "Smart vest for monitoring and support of medical staff," Int. J. Eng. Sci. Emerg. Technol., vol. 2, no. 1, pp. 59-70, 2012.

[9] A. A. Shah, Z. A. Zaidi, B. S. Chowdhry, and J. Daudpoto, "Real time face detection/monitor using Raspberry Pi and MATLAB," 
Proceedings of Conference on Application of Information and Communication Technologies, AICT'2016, 12-14 Oct. 2016, pp. 1-4

[10] P. J. Kula, Raspberry Pi Server Essentials. Packt Publishing, 2014, pp. 1-4.

[11] R. Ross, J. Whittington, and P. Huynh, "LaserTag for STEM Engagement and Education," IEEE Access, vol. 5, pp. 1930519310, 2017.

[12] D. Holden, J. Deasy, and C. Weiland, "Automatic hit detection system for real-time target hit feedback," Proceedings of the 2016 Armament Systems Forum "Shaping the Armament Enterprise to Meet Evolving Global Requirements", Fredericksburg, VA, USA, 25 28 April 2016, pp. 1-4

[13] J. E. Lebaric, R. W. Adler, M. E. Limbert, "Ultra-wideband, zero visual signature RF vest antenna for man-portable radios," Proceedings of the IEEE Military Communications Conference on Communications for NetworkCentric Operations: Creating the Information Force, MILCOM 2001, vol. 2, 2001, pp. 12911294.

[14] Tracking in Public Spaces, Datatilsynet, the Norwegian Data Protection Authority, 2016, pp. 2-20.

[15] N. Abedi, A. Bhaskar, and E. Chung, "Bluetooth and Wi-Fi MAC address based crowd data collection and monitoring : benefits, challenges and enhancement," Proceedings of the Australas. Transp. Res. Forum, 2013, pp. 117.

[16] S. Onno, C. Neumann, and O. Heen, "Conciliating remote home network access and MAC-address control," in Proceedings of the IEEE International Conference on Consumer Electronics, 2012, pp. 98-99.

[17] Gun Power Team, Creating a Culture of Leisure Sports, Airsoft Gun Sports GPR System, 2003. pp. 1-12.

[18] P. J. Soh, G. A. E. Vandenbosch, M. Mercuri, D. Schreurs, "Wearable wireless health monitoring," IEEE Microw. Mag., vol. 16, no. 4, pp. 55-70, 2015.

[19] M. Cunche, "I know your MAC address: targeted tracking of individual using Wi-Fi," Proceedings of the International Symposium on Research in Grey-Hat Hacking, 2013, pp. 118.

[20] B. Sivakumar, K. Srilatha, "Light dependent resistor (LDR) based low cost light intensity measurement circuit design (LUX Meter)," Res. J. Pharm. Biol. Chem. Sci., vol. 7, no. 3, pp. 365-373, 2016.

[21] B. S. Sriharsha, S. B. Vishnu, and V. Sanju, "Password protected locking system using Arduino," Int. J. Information Technol., vol. 8, no. 1, pp. 959-964, 2016.

[22] Project 9: Secret, in Handbook, Arduino Project, 2010, pp. 2-8.

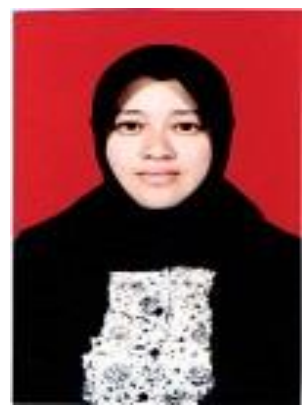

Giva Andriana Mutiara is a Lecturer at Telkom University. She obtained Master of Engineering from Bandung Institute of Technology. Active in Network and Embedded System Research Group focused on Remote Sensing, Wireless Sensor Network, and Embedded System.

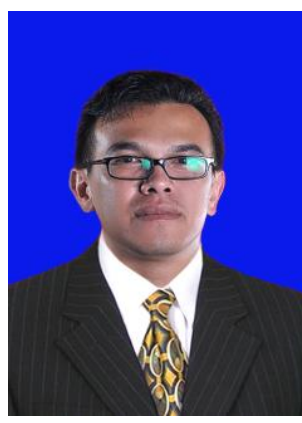

Periyadi is a lecturer at Telkom University. He obtained Master of Engineering from Langlangbuana University. Active in Network and Embedded System Research Group focused on network security, internet of thing and web application.

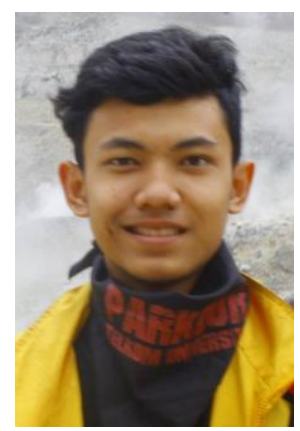

Andry Dupti Agnas is a student majoring in Computer Engineering in Applied Science Schools. Telkom University. Active in Network and Embedded System Research Group focused on Remote Sensing, Wireless Sensor Network, and Embedded System.

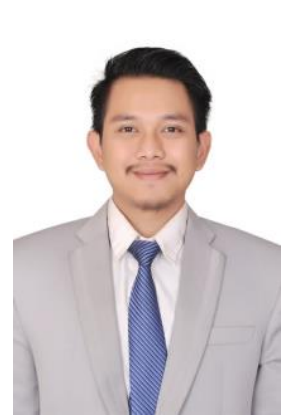

Velly Darma is a student majoring in Computer Engineering in Applied Science Schools. Telkom University. Active in Network and Embedded System Research Group focused on network security, internet of thing and web application 